\title{
Role of collagen degradation pathway in sphingomyelin synthase 2-deficient mouse skin
}

\author{
Takenaga Hiranuma ${ }^{1}$, Ken Watanabe ${ }^{2}$, Tadashi Yamashita ${ }^{3}$, Toshiro Okazaki ${ }^{4}$ and Yoshihiro Tokudome ${ }^{1^{*}}$ (i)
}

\begin{abstract}
Background: Sphingomyelin synthase (SMS) is the only enzyme that synthesizes sphingomyelin from ceramide. The role of sphingomyelin synthase in epidermis is being understood, but there is no report on its role in the dermis. Quantitative and qualitative evaluation of collagen in SMS2-deficient mice reveals the role of SMS2 in collagen production.

Methods: SMS2-deficient mice were used for in this study. The dermis thickness was measured by Elastica van Gieson staining, the collagen fiber was observed by Scanning Electron Microscopy, the collagen content by ELISA, the ceramide and sphingomyelin content by Thin Layer Chromatography, the collagen-generating and metabolizing gene expression level by RT-PCR, and MMP13 protein level was measured by western blotting.

Results: Thinner dermis in these mice compared to wild-type mice. A reduced number of collagen fibers were observed, and decreased levels of type I collagen and sphingolipids. Gene expression levels of collagen productionrelated genes in the dermis were found to be unaltered. The expression of several genes related to collagen degradation was found to be affected. The expression level of TNFa and MMP13 and MMP13 protein levels were increased relative to those of wild-type mice, while the expression level of TIMP1 was decreased.
\end{abstract}

Conclusions: These results indicate that SMS is involved not only in maintaining the sphingolipid content of the epidermal barrier but also in maintaining collagen homeostasis. Further elucidation of the role of SMS2 in the skin may lead to SMS2 comprising a new target for the treatment of skin diseases and the development of functional cosmetics.

Keywords: Sphingomyelin, Sphingomyelin synthase, Collagen, Dermis

\section{Introduction}

The skin is composed of the epidermis and dermis. To maintain the structure of the skin, the extracellular matrix in the dermis plays an important role. In particular, the quality and quantity of collagen in the dermis are important for maintaining healthy skin (Uitto et al., 1989). Collagen is known to decrease with age (Shuster

\footnotetext{
*Correspondence: tokudome@josai.ac.jp

${ }^{1}$ Faculty of Pharmacy and Pharmaceutical Sciences, Josai University, 1-1 Keyakidai, Sakado, Saitama 350-0295, Japan

Full list of author information is available at the end of the article
}

et al., 1975), and reduction and degeneration of collagen in the skin are related to wrinkle formation (Ganceviciene et al., 2012). Collagen in the dermis is biosynthesized in fibroblasts (Park et al., 2009). COL1A1 comprises the alpha chain of collagen, COL2A1 comprises the beta chain, and two alpha chains and one beta chain are crosslinked by lysyl oxidase to form the triple-helical structure of this protein (Sharma-Bhandari et al., 2015).

When exposed to ultraviolet rays, the level of reactive oxygen species increases in the skin (Masaki, 2010; Amano, 2016). In addition, it has been reported that matrix metalloproteinase I (MMP-1) levels are reduced 
by UVB irradiation and aging (Lago \& Puzzi, 2019). Thus, external stimulation may also affect the quantity of collagen in the skin by increasing or decreasing the activity of specific enzymes.

The epidermis functions as a stratum corneum barrier (van Smeden et al., 2014; Elias et al., 1981). This barrier is critical as it prevents the evaporation of water from the body and it prevents foreign bodies from entering. The stratum corneum barrier is also key because of its interstitial lipid content, and many researchers report that a high ratio of ceramide is particularly important (Elias et al., 1981). Ceramide is synthesized in the body by condensing serine and palmitoyl CoA (Holleran et al., 1990). Ceramide (Cer) is accumulated in the upper stratum granulosum layer as sphingomyelin (SM) or glucosylceramide by sphingomyelin synthase or glucosylceramide synthase, respectively (Yamaoka et al., 2004; Futerman \& Pagano, 1991). Thereafter, ceramide is released into the stratum corneum by sphingomyelinase or beta-glucocerebrosidase (Breiden \& Sandhoff, 2014).

Sphingomyelin synthase (SMS) has three isozymes, SMS1, SMS2, and SMS-related protein (SMSr), which catalyze the synthesis of sphingomyelin from ceramide (Huitema et al., 2004). SMS2-deficient mice show significantly decreased ceramide NS and AS content in the stratum corneum and decreased epidermal SM (Nomoto et al., 2018). In addition, transepidermal water loss is significantly increased. Thus, overall, the barrier function of the skin is reduced in these mice (Nomoto et al., 2018).

In the present study, we investigated the role of SMS2 in the dermis of the skin with the use of a murine SMS2knockout model. We hypothesized that a decrease in stratum corneum barrier function causes an inflammatory reaction in the skin and that a specific cell signal changes the collagen content of the dermis. The purpose of this study was, therefore, to quantitate the collagen, sphingomyelin, and ceramide content in the dermis of SMS2-deficient mice, and to analyze the mechanisms underlying the observed variations relative to wild-type mice through gene expression analysis, so as to further elucidate the function of SMS2 in the skin.

\section{Materials and methods}

\section{Animals}

SMS2-knockout (SMS2-KO) mice with a C57BL/6 background were generated by homologous recombination using targeted vectors. The mice were kept under a 12-h light/dark cycle in a conventional animal room maintained at $22 \pm 2{ }^{\circ} \mathrm{C}$ and $55 \pm 5 \%$ humidity. Sevento 9-week-old male SMS2-KO and WT mice were used for all experiments. All procedures were approved by the Ethics Committee of Josai University, and all methods were implemented in accordance with Josai University's relevant animal care and use guidelines and regulations (approval no. JU 18095).

\section{Materials}

A Mouse Type I Collagen Detection Kit, and pepsin and elastase from porcine pancreas were purchased from Chondrex, Inc. (Redmond, WA, USA). Anti-MMP13 antibody (ab39012) and anti-GAPDH antibody were purchased from Abcam, Inc. (Cambridge, Cambridgeshire, UK) and Cell Signaling Technology, Inc. (Danvers, MA, USA), respectively. Other reagents were purchased from Fujifilm Wako Pure Chemical Industries, Ltd. (Osaka, Japan) and used without further purification.

\section{Preparation of tissue sections and measurement of dermal thickness}

Skin samples were fixed in buffered formaldehyde, embedded in paraffin, sectioned $(5 \mathrm{~mm})$, and subjected to Elastica van Gieson staining for the differential staining of collagen fibers. Images were analyzed for dermal thickness using the BZ-X Analyzer (Keyence, Osaka, Japan). The dermal thickness was measured at 30 different locations per sample to calculate the average thickness.

\section{Observation of collagen fibers by scanning electron microscopy}

The full-thickness skin samples were fixed by immersion in $2.5 \%$ glutaraldehyde at $4{ }^{\circ} \mathrm{C}$ for $24 \mathrm{~h}$. The fixed skin was immersed in $2 \mathrm{~N} \mathrm{NaOH}$ for 7 days, washed with distilled water, and then dehydrated with $70,80,90$, and $100 \%$ ethanol. Samples were immersed in tert-butyl alcohol and frozen at $-20{ }^{\circ} \mathrm{C}$. The freeze-dried skin was observed for collagen fibers using a scanning electron microscope X-ray analysis system, S-3000N (Hitachi High Technologies Corporation, Tokyo, Japan).

Collagen density was calculated using collagen from the whole image by ImageJ. Collagen density was compared to the average collagen density of WT mice. Collagen density was compared to the average collagen density of WT mice. Collagen fiber width was averaged from 30 different locations per sample from the image by ImageJ.

\section{Determination of type I collagen by ELISA}

The skin tissue samples were treated with pepsin and elastase to measure the type I collagen content. Type I collagen in the skin samples was quantified according to the manufacturer's instructions, with the use of a microplate reader (SpectraMax M2e; Molecular Devices, Sunnyvale, CA, USA). From the obtained calibration curve, the obtained quantities of collagen were corrected based on the size of the area of observation and the dermal thickness, allowing calculation of the amount of collagen per unit volume. 


\section{Quantitative RT- PCR}

Total RNA was extracted from the samples with RNAiso Pius reagent according to the manufacturer's protocol, and then reverse-transcribed with the PrimeScript RT Reagent Kit. PCR reactions were performed with Power TB Green Premix Ex Taq and the amplification conditions were as follows: $95^{\circ} \mathrm{C}$ for $30 \mathrm{~s}$ for 1 cycle, 40 cycles of $95^{\circ} \mathrm{C}$ for $5 \mathrm{~s}$ and $60^{\circ} \mathrm{C}$ for $30 \mathrm{~s}$, followed by 1 cycle of 95 ${ }^{\circ} \mathrm{C}$ for $15 \mathrm{~s}, 60^{\circ} \mathrm{C}$ for $1 \mathrm{~min}$, and $95^{\circ} \mathrm{C}$ for $15 \mathrm{~s}$. The following primer sets were used: Gapdh forward $5^{\prime}$-CCATGG AGAAGGCTGGGG-3', Gapdh reverse 3'-CAACAG CGGTGCAGGTAAGTG- $5^{\prime}$, Tgf- $\beta 1$ forward $5^{\prime}$-GCA GCACGTGGAGCT GTA- $3^{\prime}$, Tgf- $\beta 1$ reverse $3^{\prime}$-CAG CCGGTTGCTGAGGTA-5', Fli1 forward $5^{\prime}$-ACTTGG CCAAATGGACGGGACTAT-3', Fli1 reverse $3^{\prime}$-CCC GTAGTCAGGACTCCCG- ${ }^{\prime}$, Smad3 forward $5^{\prime}$-CAA CATGAAGAAGGATGAAGT-3', Smad3 reverse $3^{\prime}$-AAC ACT GGAGGTAGAACTG-5', Colla1 forward $5^{\prime}$-GCC AAGAAGACATCCCTGAAG- ${ }^{\prime}$, Colla1 reverse $3^{\prime}$-TGT GGCAGATACAGATCAAGC- $5^{\prime}$, Tnf- $\alpha$ Forward $5^{\prime}-\mathrm{CCC}$ ACGTCG TAGCAAACCAC-3', Tnf- $\alpha$ reverse $3^{\prime}$-GCA GCCTTGTCCCTTGAAGA-5', Timp1 forward $5^{\prime}$-GGC ATCTGGCATCCTCTTG-3', Timp1 reverse $3^{\prime}$-GGT GGTCTCGTTGAT TTCTGG-5', Mmp13 forward 5'-GCCAGAACTTCCCAACCA T-3', Mmp13 reverse 3'-TCAGAGCCCAGAATTTTCTCC-5', respectively. The quantity of each transcript was analyzed with the StepOnePlus Real-Time PCR System (Applied Biosystems, Foster City, CA, USA) and data were normalized to that of the internal control, glyceraldehyde-3-phosphate dehydrogenase (Gapdh), according to the $\Delta \Delta \mathrm{Ct}$ method (Livak \& Schmittgen, 2001).

\section{Western blotting}

Skin samples were homogenized with PT 1200 E (Kinematia AG, Lucerne, Switzerland) in radioimmunoassay buffer $(50 \mathrm{mM}$ Tris- $\mathrm{HCl} \mathrm{pH}$ 8.0, $150 \mathrm{mM} \mathrm{NaCl}, 0.5 \%$ sodium deoxycholate, $0.1 \%$ sodium dodecyl sulfate, $1 \%$ Nonidet P-40) containing a protease inhibitor cocktail. Skin extracts were prepared by centrifugation at $18,000 \times g$ at $4{ }^{\circ} \mathrm{C}$ for $15 \mathrm{~min}$, and the supernatants were kept for further experiments. Sample protein concentrations were determined with the BCA (bicinchoninic acid) protein assay. Western blotting membranes were blocked for $1 \mathrm{~h}$ at room temperature in 5\% skimmed milk. The membranes were then incubated overnight (approximately $16 \mathrm{~h}$ ) at $4{ }^{\circ} \mathrm{C}$ with primary antibodies comprising anti-MMP-13 (1:3000) and anti-GAPDH (1:3000). After incubation, the membranes were then incubated at room temperature with the secondary antibody, consisting of HRP-conjugated donkey anti-rabbit IgG (1:4000). The immunoreactive bands were visualized using ECL Prime
Western Blotting Detection Reagent. The signals were detected with the Molecular Imager ChemiDoc XRS System (Bio-Rad Laboratories), band density was analyzed using Image Lab software (Bio-Rad Laboratories), and each sample was normalized against the GAPDH signal for equal protein loading control in each experiment.

\section{Lipid extraction and quantification of sphingolipids in the dermis}

Full-thickness skin sections were collected from each mouse and the subcutaneous fat was removed. Fullthickness skin was separated into the epidermis and dermis with EDTA. After the dermis was collected with a 6-mm biopsy trepan, it was lyophilized and then weighed. Total lipids in the dermis were extracted with a chloroform:methanol solution $(2: 1, \mathrm{v} / \mathrm{v})$. These extracted samples were spotted onto HPTLC Silica Gel 60 (Merck, Frankfurt, Darmstadt, Germany). The developing solvents for sphingomyelin and ceramides comprised chloroform:methanol:acetic acid:water at 50:30:8:4 (v/v) and chloroform:methanol:acetic acid at 190:90:1 (v/v), respectively. The bands were visualized by spraying $10 \%$ copper sulfate and $8 \%$ phosphoric acid onto the HPTLC plate and heating the plate at $180{ }^{\circ} \mathrm{C}$ for $10 \mathrm{~min}$. HPTLC plates were imaged with a Molecular Imager ChemiDoc XRS System, and SM and Cer were quantified from the band densities. SM and Cer quantities were all corrected for dermal weight.

\section{Statistical analysis}

Analyses were performed with SAS software version 9.2 (SAS Institute, Cary, NC, USA). All data are presented as the mean \pm standard deviation (SD). Indicated $p$ values were derived from the Student's $t$ test, and $p<0.05$ was considered statistically significant.

\section{Results \\ Thickness of SMS2-deficient mouse dermis}

The skin of SMS2-deficient and WT mice was subjected to Elastica van Gieson staining, which is specific for collagen, thereby allowing measurement of the dermal thickness (Fig. 1a). The dermal thickness of SMS2KO mice was $146.9 \pm 27.7 \mu \mathrm{m}$, which was significantly less $(p$ $<0.05)$ than that of WT mice $(175.3 \pm 24.7 \mu \mathrm{m})$ (Fig. 1b).

\section{Observation of collagen fibers in the SMS2-deficient mouse dermis by scanning electron microscopy (SEM)} Using SEM, the collagen fibers density in the SMS2-deficient mouse dermis was found to be reduced compared to that of WT mice (Fig. 2a-c). The diameter of the collagen fiber width was not different between SMS2-deficient mice and WT mice (Fig. 2a, b, d). 

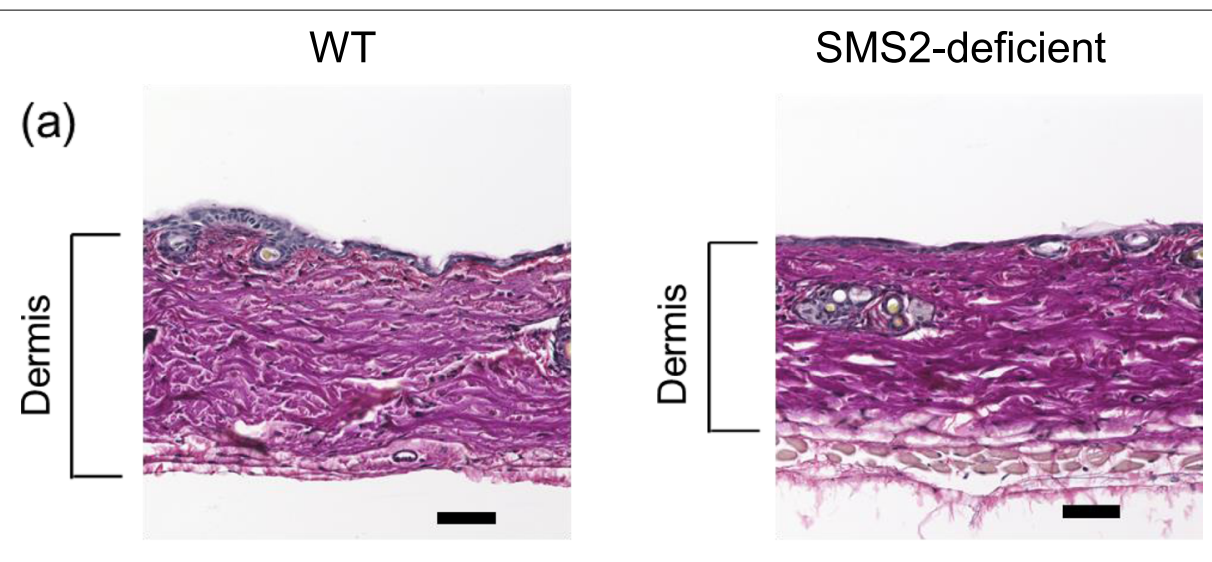

(b)

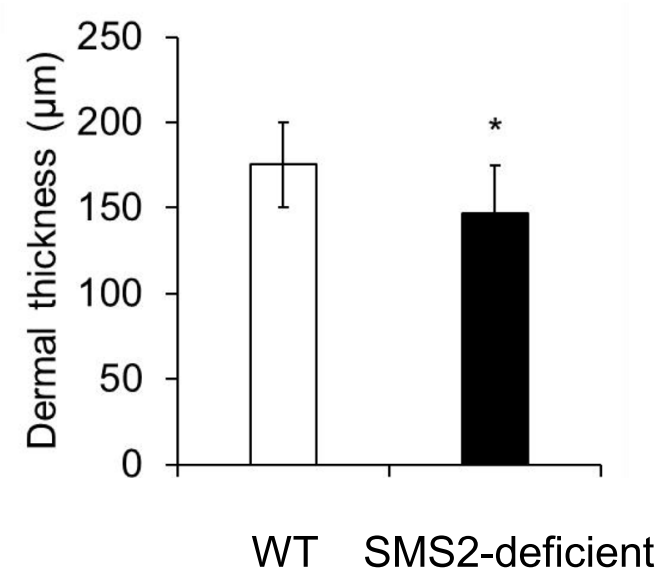

Fig. 1 Elastica van Gieson staining of SMS2-deficient mice skin to determine the dermal thickness. a Images of stained WT and SMS2-deficient mouse skin. Scale bar $=50 \mu \mathrm{m}$. $\mathbf{b}$ Quantification of the dermal thickness in the two mouse groups. Data are expressed as the mean \pm SD, and statistical analysis was performed with the Student's $t$ test $\left({ }^{*} p<0.05\right)$

\section{Quantitation of type I collagen in the SMS2-deficient mouse dermis by ELISA}

Based on ELISA analysis, the type I collagen content in the dermis of SMS2-deficient mice was $6.5 \pm 1.9 \mu \mathrm{g} /$ $\mathrm{mm}^{3}$, which was significantly lower $(p<0.05)$ than that of WT mice $\left(9.2 \pm 1.5 \mu \mathrm{g} / \mathrm{mm}^{3}\right)$ (Fig. 3).

\section{Sphingolipid (sphingomyelin and ceramide) content in the SMS2KO-deficient mouse dermis}

HPTLC was used to analyze the sphingolipid content of the dermis. The SM content of the SMS2KO-deficient mouse dermis was $2.9 \pm 0.7 \mu \mathrm{g} / \mathrm{mg}$ dermis, which was significantly lower $(p<0.01)$ than that of WT mice $(4.8$ $\pm 0.6 \mu \mathrm{g} / \mathrm{mg}$ dermis) (Fig. 4a). The Cer [NS] content of the SMS2-deficient mouse dermis was $2.1 \pm 0.6 \mu \mathrm{g} / \mathrm{mg}$ dermis, which was significantly lower $(p<0.05)$ than that of WT mice (3.1 $\pm 0.6 \mu \mathrm{g} / \mathrm{mg}$ dermis) (Fig. 4b). In contrast, the Cer [NP] content of the SMS2-deficient mouse dermis was similar to that of WT mice (Fig. 4c). The Cer
[AS] and Cer [AP] contents were not detected by HPTLC (data not shown).

\section{Expression of genes related to collagen production} and metabolism in SMS2-deficient mouse skin

The expression of genes related to collagen production (Tgf- $\beta 1$, Fli1, Smad3, and Col1a1) was quantified by RTPCR in the SMS2KO mouse skin (Fig. 5a-d). No changes in gene expression were observed compared with the WT mice. On the other hand, the expression of the $\operatorname{Tn} f-\alpha$, Timp1, and Mmp13 genes involved in collagen metabolism was altered by a 2.1 -fold increase, 0.4 -fold decrease, and 3.4-fold increase compared to that of the WT mice, respectively (Fig. $5 \mathrm{e}-\mathrm{g}$ ), with the first two values being statistically significant $(p<0.05)$.

\section{MMP13 protein expression level in SMS2-deficient mouse skin}

Total protein was extracted from the skin of WT and SMS2-deficient mice and the protein expression of 
(a)

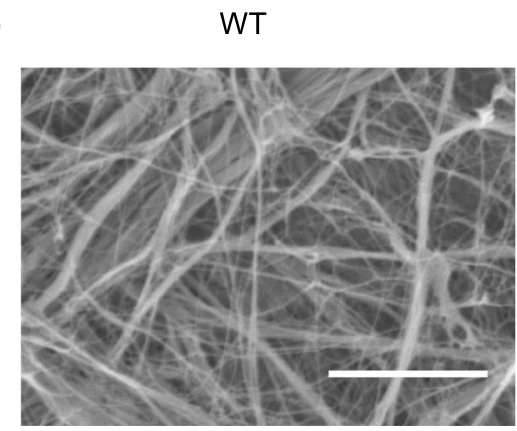

(c)

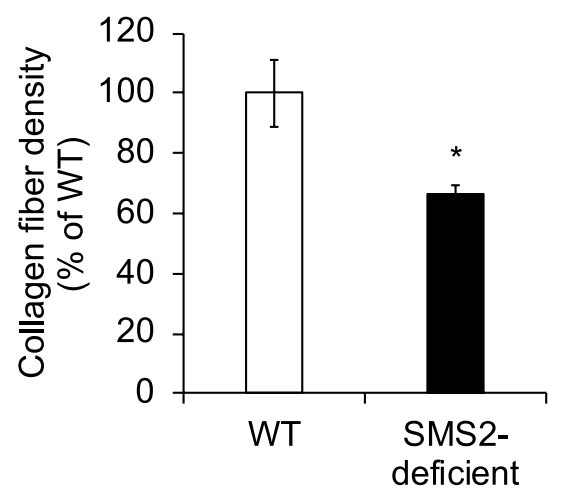

(b)

SMS2-deficient

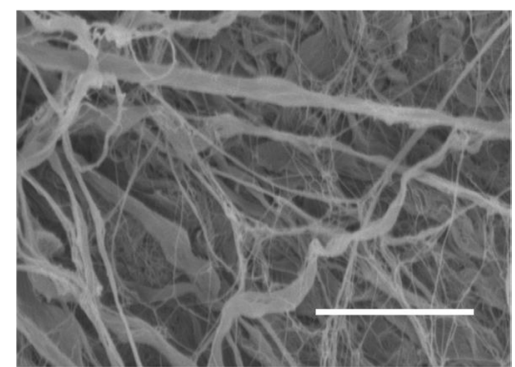

(d)

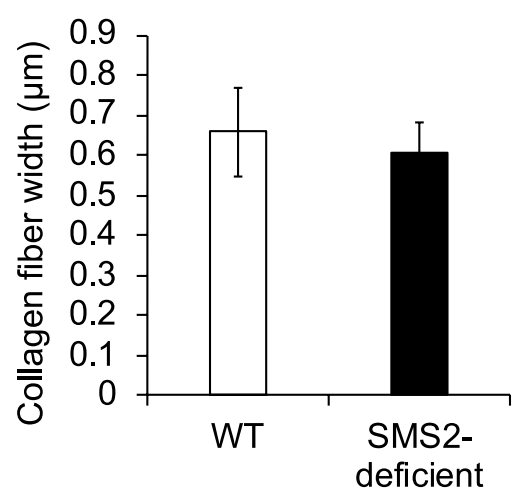

Fig. 2 Skin collagen fiber images prepared using scanning electron microscopy of WT (a) and SMS2-deficient (b) mice skin samples. Scale bar = $10 \mu \mathrm{m}$. Collagen fiber density (c). Collage fiber width (d). Data are expressed as the mean \pm SD, and statistical analysis was performed with the Student's $t$ test $\left({ }^{*} p<0.05\right)$

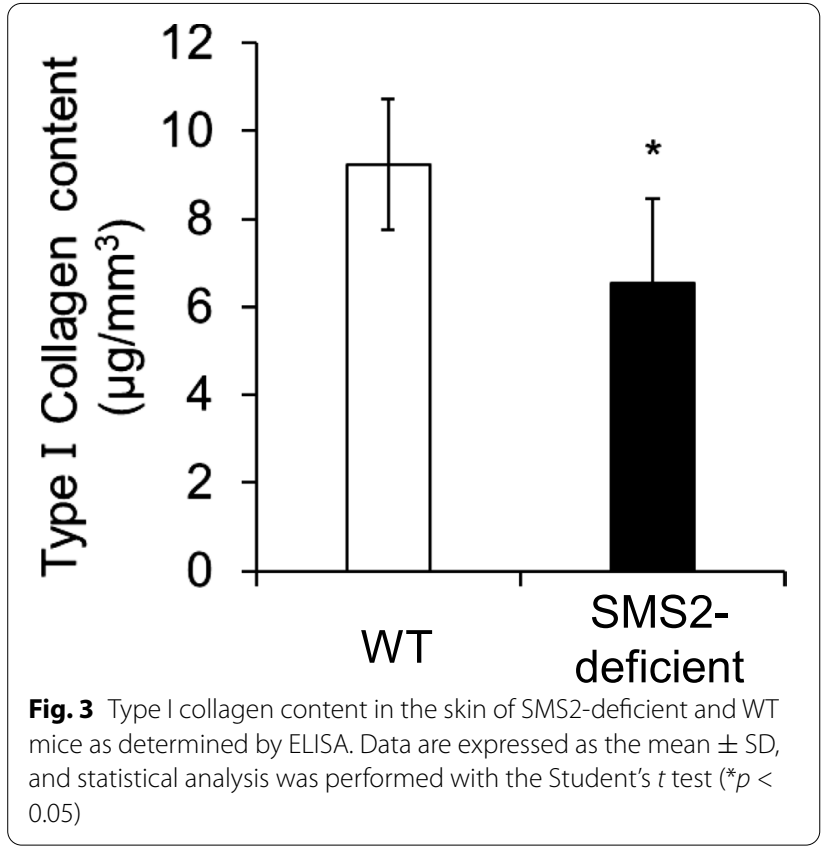

MMP13 in the skin was quantified by western blotting (Fig. 6). MMP13 protein expression level in the SMS2deficient mouse skin was significantly increased ( $p<$ 0.05 ) by 6.9 -fold compared to that in the WT mouse skin.

\section{Discussion}

The purpose of this study was to elucidate the effects of SMS deficiency on the dermis in terms of both collagen production and metabolism, with the use of SMS2-deficient mice. First, based on Elastica van Gieson staining, the SMS2KO mice were observed to have a significantly thinner dermis than the WT mice (Fig. 1). It has been reported that the skin thins during aging as a result of decreasing levels of collagen (Shuster et al., 1975). Thus, we hypothesized that the reduced dermal thickness in the SMS2-deficient mice might have been due to a decrease in collagen content in the dermis. Indeed, observation of collagen fibers in the dermis by SEM showed fewer collagen fibers in the dermis of SMS2-deficient mice compared to that of WT mice (Fig. 2). However, there was no difference in the width of the collagen fibers between WT mice and SMS2-deficient mice. We further tested this finding by also measuring the collagen content of 

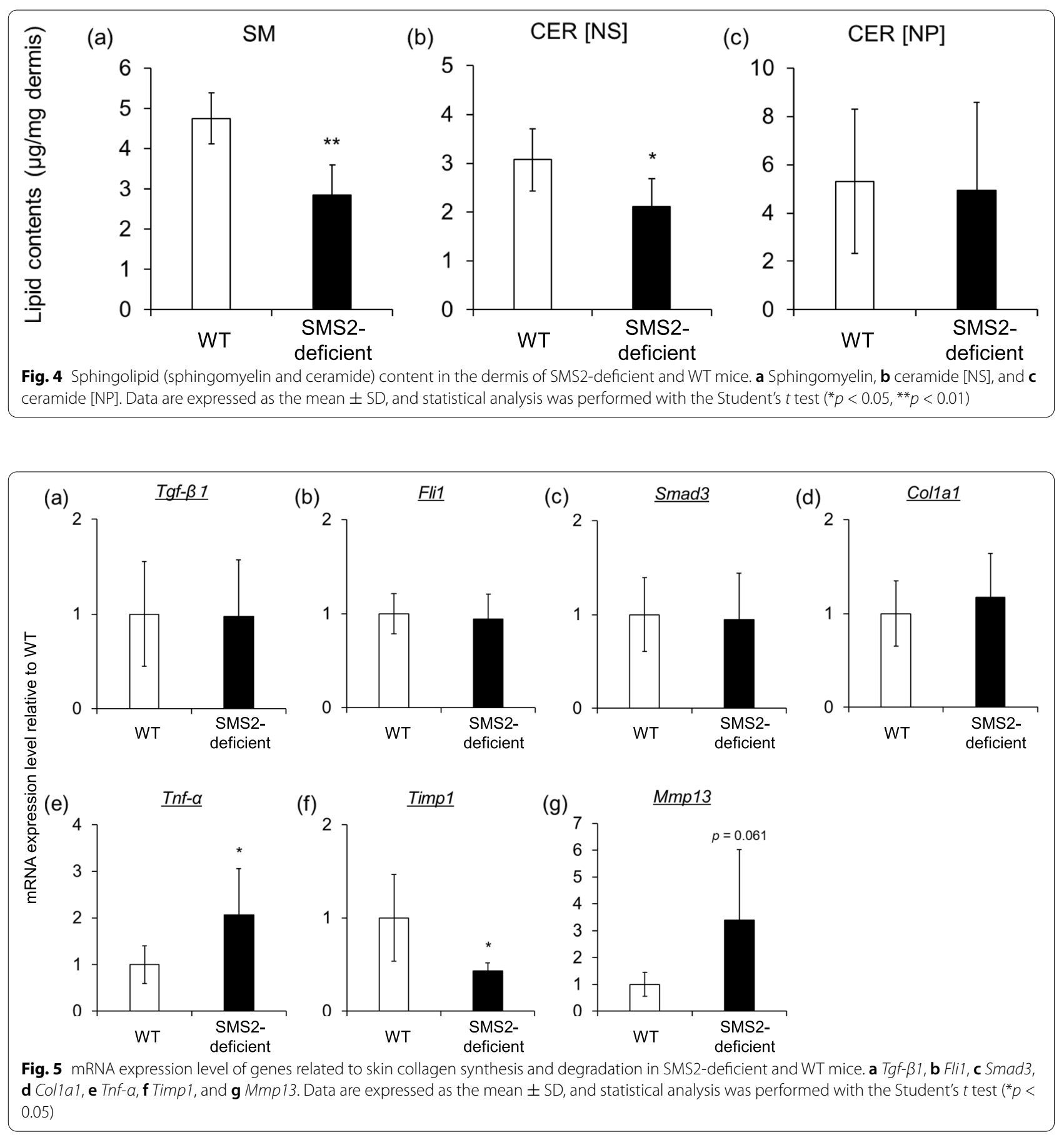

SMS2-deficient mice and WT mice by ELISA, which indicated that the content of type 1 collagen in the skin of the SMS2-deficient mice was significantly decreased compared to that of WT mice (Fig. 3). Therefore, it is likely that SMS2 deficiency reduces the collagen content of the skin.

SMS2-deficient mice are also reported to have decreased brain and epidermal SM levels (Nomoto et al., 2018; Zhang et al., 2011). We next quantified the SM and Cer content of the dermis of SMS2-deficient mice by HPTLC. The dermis of the SMS2-deficient mice was observed to contain significantly less SM and Cer [NS] compared to that of WT mice (Fig. 4). However, the mechanism underlying the effect of SMS2 deficiency on Cer levels in the dermis remains unknown. 


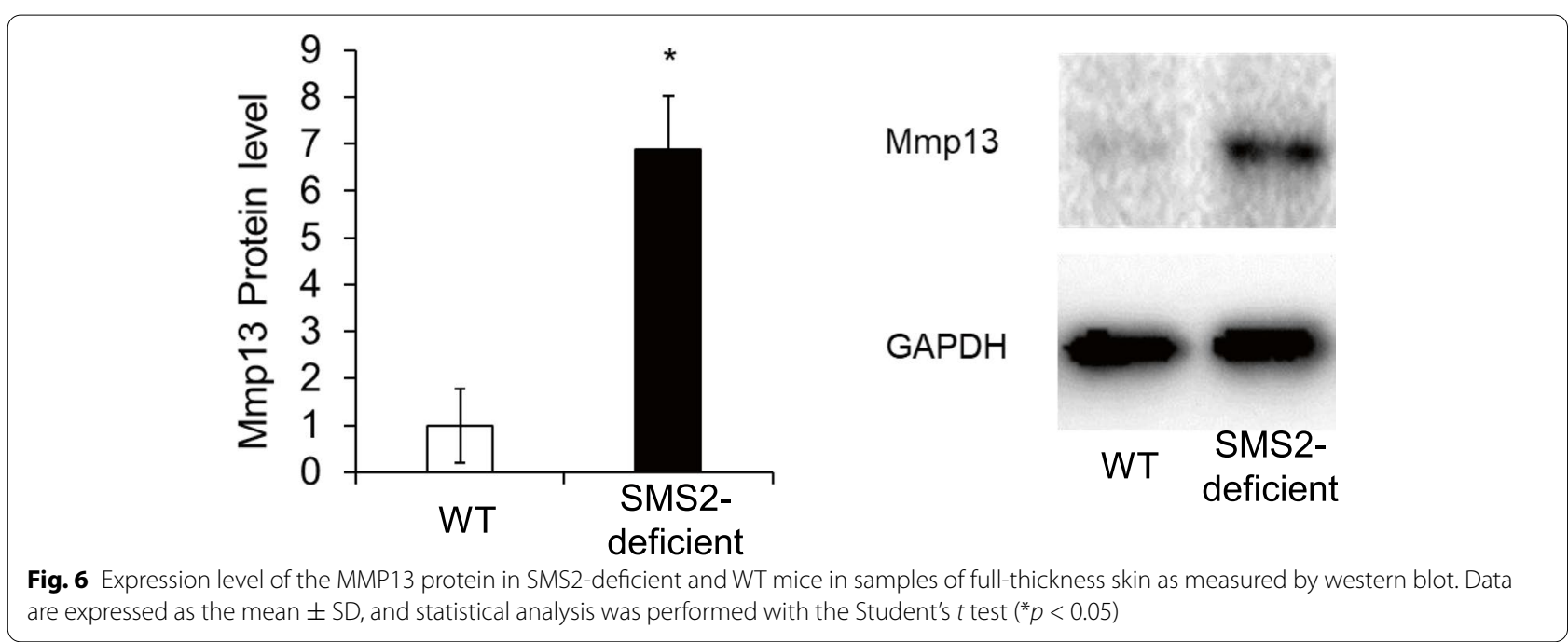

Finally, we focused on the expression of genes involved in collagen production and metabolism in the skin to investigate the mechanism underlying collagen reduction in the SMS2-deficient mice. First, we determined whether SMS2-deficient mice have a reduced capacity for producing collagen in the skin. In general, the production of collagen is initiated by the translocation of Smad3 into the nucleus after it is phosphorylated through TGF- $\beta$ stimulation (Blobe et al., 2000; Shi \& Massagué, 2003). However, using RT-PCR, we found no difference in the transcript levels of Tgf- $\beta 1, S m a d 3$, or Col1a1 between the WT and SMS2-deficient mice. It is also known that the friend leukemia integration 1 transcription factor (Fli1) is decreased in the skin of systemic sclerosis (SSc) patients and that the overexpression of Fli1 suppresses type I collagen production (Kubo et al., 2003). Therefore, we also measured the transcript levels of Fil1 in the SMS2-deficient mice. However, no differences in expression were found in comparison with the WT mice. Overall, these results suggested that the decrease we observed in type I collagen in the skin of the SMS2-deficient mice was not affected via changes in collagen production through TGF- $\beta$ stimulation.

We next analyzed the expression level of collagen metabolism-related genes in the SMS2-deficient mice. AP-1 is known to be phosphorylated by TNF- $\alpha$ and then translocated into the nucleus, where it represses MMPs and degrades collagen (Wlaschek et al., 1997; Barr et al., 1999; Rosette \& Karin, 1996; Angel et al., 2001; Quan et al., 2009). TIMP also regulates MMP activity (Brew \& Nagase, 2010). Here, the transcript level of TNF- $\alpha$ in the skin of SMS2-deficient mice was found to be significantly higher than that of WT mice. In addition, the expression of Timp1 and Mmp13 in the skin of SMS2-deficient mice was significantly decreased and increased, respectively, compared to that of WT mice. TNF- $\alpha$ levels are reportedly increased in the keratinocytes of patients with atopic dermatitis (Jung et al., 2014). TNF- $\alpha$ is also involved in the development of psoriasis, and infliximab, a TNF- $\alpha$ antagonist, is used for the treatment of this skin disease (Sato et al., 2014; Menter et al., 2007). Thus, based on these data and our results, it is possible that TNF- $\alpha$ was increased in the dermis of the SMS2-deficient mice as a result of the decreased level of ceramide in the skin of these mice or through the deterioration of the barrier function of the skin. Furthermore, ceramide has been reported to promote TIMP1 production in keratinocytes (Buisson-Legendre et al., 2000). Therefore, in SMS2-deficient mice, the decreased ceramide content in the stratum corneum may have reduced the level of Timp1 gene expression in the dermis.

MMP13 is known as a major collagenase in rodents (Balbín et al., 2001; Vincenti et al., 1998), and it has been reported that UV irradiation increases the expression of MMP13 in mouse skin (Li et al., 2017). MMP13 is induced by the expression of the inflammatory cytokines, IL-1 and TNF- $\alpha$ (Mengshol et al., 2001; Mariani et al., 1998). Therefore, MMP13 may be induced by an increase in the expression level of Tnf- $\alpha$ and a concomitant decrease in the expression level of Timp1 in SMS2deficient mice. To investigate this, we extracted the total protein from the mouse skin of the two experimental groups, and the protein expression level of MMP13 was quantified by western blotting. The protein expression level of MMP13 in the skin of the SMS2-deficient mice was found to be significantly increased compared to that of the WT mice. This strongly suggests that MMP13 is involved in the reduction in collagen content in the skin 
of SMS2-deficient mice. Thus, while collagen production in the skin of SMS2-deficient mice is similar to that of WT mice, changes in Tnf- $\alpha$ and Timp1 expression in the former result in the loss of homeostasis in the metabolism of collagen by markedly increasing the expression of Mmp13, thereby leading to increased degradation of type I collagen in these knockout mice and reduced overall collagen content in the dermis.

\section{Conclusion}

SMS deficiency has been reported to reduce epidermal barrier function. However, the role of SMS in the dermis remained unknown. In the present study, SMS2 deficiency in the mouse skin was not observed to affect collagen production. Rather, the results suggested that the homeostasis of collagen metabolism was affected through a marked increase in the degradation of collagen. Overall, the data revealed that the promotion of collagen degradation comprises one of the roles of SMS2 in the dermis. In the future, it is hoped that further elucidation of the role of SMS in the skin will offer a new target for the treatment of skin diseases and for the development of functional cosmetics.

\begin{abstract}
Abbreviations
AD: Atopic dermatitis; aCDase: Acidic ceramidase; alkCDase: Alkaline ceramidase; aSMase: Acidic sphingomyelinase; BGCase: $\beta$-glucocerebrosidase; CER: Ceramide; DMPC: Dimilystoylphosphatidylcholine; GC: Glucosylceramide; GCS: GC synthase; HPLC: High performance liquid chromatography; HPTLC: High performance thin layer chromatography; KO: Knockout; NBD: Nitrobenzoxadiazole; PMSF: Phenylmethylsulfonylfluoride; SEM: Scanning electron microscope; SC: Stratum corneum; SD: Standard deviation; SM: Sphingomyelin; SMase: Sphingomyelinase; SMS: SM synthase; SMSr: SMS-related protein; TEWL: Transepidermal water loss; WT: Wild type.
\end{abstract}

\section{Acknowledgements}

We thank Natasha Beeton-Kempen, Ph.D., from Edanz Group (www.edanzediti ng.com/ac) for editing a draft of this manuscript.

\section{Authors' contributions}

TH KW, TY, TO, and YT contributed to the conception and design of this study. $\mathrm{TH}$ and $\mathrm{KW}$ performed research. $\mathrm{KW}$, TY, and TO contributed the knockout mice for the study. TH, KW, TY, TO, and YT analyzed the data. TH and YT wrote the paper. All authors read the manuscript and approved the submission.

\section{Funding}

This work was supported by the JSPS KAKENHI Grant Number JP18K06604 to Y.T.

\section{Availability of data and materials}

The datasets analyzed during the current study are available from the corresponding author on reasonable request.

\section{Declarations}

\section{Ethics approval and consent to participate}

All procedures were approved by the Ethics Committee of Josai University and all methods were implemented in accordance with Josai University's relevant animal care and use guidelines and regulations (approval no. JU 18095).
Consent for publication

Not applicable

\section{Competing interests}

The authors declare that they have no competing interests.

\section{Author details}

${ }^{1}$ Faculty of Pharmacy and Pharmaceutical Sciences, Josai University, 1-1 Keyakidai, Sakado, Saitama 350-0295, Japan. ${ }^{2}$ Department of Bone and Joint Disease, National Center for Geriatrics and Gerontology, 7-430 Morioka, Obu, Aichi 474-8511, Japan. ${ }^{3}$ School of Veterinary Medicine, Azabu University, 1-17-71 Fuchinobe, Chuo-ku, Sagamihara, Kanagawa 252-5201, Japan. ${ }^{4}$ Research Institute for Bioresources and Biotechnology, Ishikawa Prefectural University, 1-308 Suematsu, Nonoichi, Ishikawa 921-8836, Japan.

Received: 30 September 2020 Accepted: 20 October 2021 Published online: 28 October 2021

\section{References}

Amano S. Characterization and mechanisms of photoageing-related changes in skin. Damages of basement membrane and dermal structures. Exp Dermatol. 2016;25(Suppl 3):14-9. https://doi.org/10.1111/exd.13085.

Angel P, Szabowski A, Schorpp-Kistner M. Function and regulation of AP-1 subunits in skin physiology and pathology. Oncogene. 2001;20:2413-23. https://doi.org/10.1038/sj.onc.1204380.

Balbín M, Fueyo A, Knäuper V, et al. Identification and enzymatic characterization of two diverging murine counterparts of human interstitial collagenase (MMP-1) expressed at sites of embryo implantation. J Biol Chem. 2001;276:10253-62. https://doi.org/10.1074/jbc.M009586200.

Barr RM, Walker SL, Tsang W, et al. Suppressed alloantigen presentation, increased TNF-alpha, IL-1, IL-1Ra, IL-10, and modulation of TNF-R in UVirradiated human skin. J Invest Dermatol. 1999;1 12:692-8. https://doi.org/ 10.1046/.1.1523-1747.1999.00570.x.

Blobe GC, Schiemann WP, Lodish HF. Role of transforming growth factor beta in human disease. N Engl J Med. 2000;342:1350-8. https://doi.org/10. 1056/NEJM200005043421807.

Breiden B, Sandhoff K. The role of sphingolipid metabolism in cutaneous permeability barrier formation. Biochim Biophys Acta. 2014;1841:441-52. https://doi.org/10.1016/j.bbalip.2013.08.010.

Brew K, Nagase $\mathrm{H}$. The tissue inhibitors of metalloproteinases (TIMPs): an ancient family with structural and functional diversity. Biochim Biophys Acta. 2010;1803:55-71. https://doi.org/10.1016/j.bbamcr.2010.01.003.

Buisson-Legendre N, Emonard H, Bernard P, Hornebeck W. Relationship between cell-associated matrix metalloproteinase 9 and psoriatic keratinocyte growth. J Invest Dermatol. 2000;115:213-8. https://doi.org/ 10.1046/j.1523-1747.2000.00059.x.

Elias PM, Cooper ER, Korc A, Brown BE. Percutaneous transport in relation to stratum corneum structure and lipid composition. J Invest Dermatol. 1981;76:297-301. https://doi.org/10.1111/1523-1747.ep12526137.

Futerman AH, Pagano RE. Determination of the intracellular sites and topology of glucosylceramide synthesis in rat liver. Biochem J. 1991;280(Pt 2):295-302. https://doi.org/10.1042/bj2800295.

Ganceviciene R, Liakou Al, Theodoridis A, et al. Skin anti-aging strategies. Dermato-Endocrinology. 2012;4:308-19. https://doi.org/10.4161/derm. 22804.

Holleran WM, Williams ML, Gao WN, Elias PM. Serine-palmitoyl transferase activity in cultured human keratinocytes. J Lipid Res. 1990;31:1655-61.

Huitema K, van den Dikkenberg J, Brouwers JF, Holthuis JC. Identification of a family of animal sphingomyelin synthases. EMBO J. 2004;23:33-44. https://doi.org/10.1038/sj.emboj.7600034.

Jung M, Choi J, Lee S-A, et al. Pyrrolidone carboxylic acid levels or caspase-14 expression in the corneocytes of lesional skin correlates with clinical severity, skin barrier function and lesional inflammation in atopic dermatitis. J Dermatol Sci. 2014;76:231-9. https://doi.org/10.1016/j.jderm sci.2014.09.004

Kubo M, Czuwara-Ladykowska J, Moussa O, et al. Persistent down-regulation of Fli1, a suppressor of collagen transcription, in fibrotic scleroderma 
skin. The Am J Pathol. 2003;163:571-81. https://doi.org/10.1016/S00029440(10)63685-1.

Lago JC, Puzzi MB. The effect of aging in primary human dermal fibroblasts. PLoS One. 2019;14:e0219165. https://doi.org/10.1371/journal.pone.02191 65.

Li Z, Niu X, Xiao S, Ma H. Retinoic acid ameliorates photoaged skin through RAR-mediated pathway in mice. Mol Med Rep. 2017;16:6240-7. https:// doi.org/10.3892/mmr.2017.7336.

Livak KJ, Schmittgen TD. Analysis of relative gene expression data using realtime quantitative PCR and the 2- $\triangle \triangle C T$ method. Methods. 2001;25:402-8. https://doi.org/10.1006/meth.2001.1262.

Mariani TJ, Sandefur S, Roby JD, Pierce RA. Collagenase-3 induction in rat lung fibroblasts requires the combined effects of tumor necrosis factor-alpha and 12-lipoxygenase metabolites: a model of macrophage-induced, fibroblast-driven extracellular matrix remodeling during inflammatory lung injury. Mol Biol Cell. 1998;9:1411-24. https://doi.org/10.1091/mbc.9. 6.1411.

Masaki H. Role of antioxidants in the skin: anti-aging effects. J Dermatol Sci. 2010;58:85-90. https://doi.org/10.1016/j.jdermsci.2010.03.003.

Mengshol JA, Vincenti MP, Brinckerhoff CE. IL-1 induces collagenase-3 (MMP13) promoter activity in stably transfected chondrocytic cells: requirement for Runx-2 and activation by p38 MAPK and JNK pathways. Nucleic Acids Res. 2001;29:4361-72. https://doi.org/10.1093/nar/29.21.4361.

Menter A, Feldman SR, Weinstein GD, et al. A randomized comparison of continuous vs intermittent infliximab maintenance regimens over 1 year in the treatment of moderate-to-severe plaque psoriasis. J Am Acad Dermatol. 2007:56:31.e1-15. https://doi.org/10.1016/j.jaad.2006.07.017.

Nomoto K, Itaya Y, Watanabe K, et al. Epidermal permeability barrier function and sphingolipid content in the skin of sphingomyelin synthase 2 deficient mice. Exp Dermatol. 2018;27:827-32. https://doi.org/10.1111/ exd.13497.

Park HJ, Cho DH, Kim HJ, et al. Collagen synthesis is suppressed in dermal fibroblasts by the human antimicrobial peptide LL-37. J Invest Dermatol. 2009;129:843-50. https://doi.org/10.1038/jid.2008.320.

Quan T, Qin Z, Xia W, et al. Matrix-degrading metalloproteinases in photoaging. J Investig Dermatol Symp Proc. 2009;14:20-4. https://doi.org/10. 1038/jidsymp.2009.8.

Rosette C, Karin M. Ultraviolet light and osmotic stress: activation of the JNK cascade through multiple growth factor and cytokine receptors. Science. 1996;274:1194-7. https://doi.org/10.1126/science.274.5290.1194.
Sato K, Takaishi M, Tokuoka S, Sano S. Involvement of TNF-a converting enzyme in the development of psoriasis-like lesions in a mouse model. PLoS One. 2014;9:e1 12408. https://doi.org/10.1371/journal.pone.0112408.

Sharma-Bhandari A, Park S-H, Kim J-Y, et al. Lysyl oxidase modulates the osteoblast differentiation of primary mouse calvaria cells. Int J Mol Med. 2015;36:1664-70. https://doi.org/10.3892/ijmm.2015.2384.

Shi Y, Massagué J. Mechanisms of TGF-beta signaling from cell membrane to the nucleus. Cell. 2003;113:685-700. https://doi.org/10.1016/s00928674(03)00432-x

Shuster S, Black MM, McVitie E. The influence of age and sex on skin thickness, skin collagen and density. Br J Dermatol. 1975;93:639-43. https://doi.org/ 10.1111/j.1365-2133.1975.tb05113.x.

Uitto J, Olsen DR, Fazio MJ. Extracellular matrix of the skin: 50 years of progress. J Invest Dermatol. 1989;92:61S-77S. https://doi.org/10.1111/1523-1747. ep13075039.

van Smeden J, Janssens M, Gooris GS, Bouwstra JA. The important role of stratum corneum lipids for the cutaneous barrier function. Biochim Biophys Acta. 2014;1841:295-313. https://doi.org/10.1016/j.bbalip.2013.11.006.

Vincenti MP, Coon Cl, Mengshol JA, et al. Cloning of the gene for interstitial collagenase-3 (matrix metalloproteinase-13) from rabbit synovial fibroblasts: differential expression with collagenase-1 (matrix metalloproteinase-1). Biochem J. 1998;331(Pt 1):341-6. https://doi.org/10.1042/ bj3310341.

Wlaschek M, Wenk J, Brenneisen P, et al. Singlet oxygen is an early intermediate in cytokine-dependent ultraviolet-A induction of interstitial collagenase in human dermal fibroblasts in vitro. FEBS Lett. 1997;413:239-42. https:// doi.org/10.1016/s0014-5793(97)00919-8.

Yamaoka S, Miyaji M, Kitano T, et al. Expression cloning of a human cDNA restoring sphingomyelin synthesis and cell growth in sphingomyelin synthase-defective lymphoid cells. J Biol Chem. 2004;279:18688-93. https://doi.org/10.1074/jbc.M401205200.

Zhang Y, Dong J, Zhu X, et al. The effect of sphingomyelin synthase 2 (SMS2) deficiency on the expression of drug transporters in mouse brain. Biochem Pharmacol. 2011;82:287-94. https://doi.org/10.1016/j.bcp.2011. 04.009.

\section{Publisher's Note}

Springer Nature remains neutral with regard to jurisdictional claims in published maps and institutional affiliations.
Ready to submit your research? Choose BMC and benefit from:

- fast, convenient online submission

- thorough peer review by experienced researchers in your field

- rapid publication on acceptance

- support for research data, including large and complex data types

- gold Open Access which fosters wider collaboration and increased citations

- maximum visibility for your research: over $100 \mathrm{M}$ website views per year

At BMC, research is always in progress.

Learn more biomedcentral.com/submissions 